\title{
An ergonomic modular foot platform for isometric force/torque measurements in poststroke functional assessment: A pilot study
}

\author{
Stefano Mazzoleni, PhD; ${ }^{*}$ Jo Van Vaerenbergh, PhD; ${ }^{2}$ Emma Stokes, PhD; ${ }^{3}$ Gábor Fazekas, MD, PhD; ${ }^{4}$ Paolo \\ Dario, PhD; ${ }^{1}$ Eugenio Guglielmelli, $\mathbf{P h D}^{\mathbf{5}}$ \\ ${ }^{1}$ The BioRobotics Institute, Scuola Superiore Sant'Anna, Pisa, Italy; ${ }^{2}$ Center for Multidisciplinary Approach and Tech- \\ nology, Brussels, Belgium; ${ }^{3}$ School of Physiotherapy, Trinity College Dublin, Dublin, Ireland; ${ }^{4}$ National Institute for \\ Medical Rehabilitation, Budapest, Hungary; ${ }^{5}$ Laboratory of Biomedical Robotics and Biomicrosystems, Università \\ Campus Bio-Medico, Rome, Italy
}

\begin{abstract}
The main goal of this article is to present the design, technical development, and preliminary validation of an innovative mechatronic device for force/torque measurements taken from the human foot using pilot data. The device, formed by a mobile platform equipped with two six-axis force/ torque sensors, was used to perform accurate quantitative measurements during isometric exercises, aimed at performing functional assessment tests in poststroke patients undergoing a rehabilitation treatment. Results from pilot data provide a validation of the device. A large clinical trial has been planned to test whether the platform can be used in the clinical practice. We suggest that measurements of ground reaction forces taken from the foot of poststroke patients during the initiation of activities of daily living tasks can provide information about their motor recovery and enlighten possible areas of application, ranging from isometric motor exercise in neurorehabilitation to foot-based human-machine interface.
\end{abstract}

Key words: assessment, ergonomic design, foot function, force/torque measurements, ground reaction forces, humanmachine interface, isometric measurements, mechatronics, rehabilitation, stroke.

\section{INTRODUCTION}

The functional assessment of the motor performance of the foot and its rehabilitation after neurological injuries (e.g., stroke, traumatic brain injury, spinal cord injury) represents a fundamental stage for recovery of activity of daily living (ADL) tasks, essential for independent living [1-4]. Different biomechatronic applications based on the detection of foot pressure for the compensation of sensory and motor loss in disabled subjects have been proposed recently [5-6]. Functional recovery of a neurologically impaired patient can rely on the analysis of dysfunctions of sensorimotor control. The analysis of the great toe during motor recovery is important from a clinical point of view since it has consequences on locomotion; the role of the great toe on the motor recovery of poststroke patients (PSs) has recently been investigated [7]. From a functional assessment perspective, this study focuses on the sitting posture during ADL tasks [8].

\footnotetext{
Abbreviations: $\mathrm{ADL}=$ activity of daily living, $\mathrm{FM}=$ FuglMeyer, $\mathrm{F} / \mathrm{T}=$ force/torque, $\mathrm{H}$ = height, $\mathrm{HMI}=$ human-machine interface, $\mathrm{HU}=$ height of the user from the foot platform, $\mathrm{L}=$ large, $\mathrm{M}=$ medium, MAS = Motor Assessment Scale, PS = poststroke patient, $\mathrm{S}=$ small.

*Address all correspondence to Stefano Mazzoleni, PhD; The BioRobotics Institute, Scuola Superiore Sant'AnnaPolo Sant'Anna Valdera, Viale R. Piaggio, 34-56025 Pontedera (Pisa)-Italy; +39-050-883132; fax +39-050-883101. Email: s.mazzoleni@sssup.it http://dx.doi.org/10.1682/JRRD.2011.03.0059
} 
The study of the foot's forces and torques during isometric exercises is rather limited so far [9-11]. Some actuated devices were recently presented as haptic tools for foot rehabilitation [12-14].

This article presents an innovative device for monolateral isometric force/torque $(\mathrm{F} / \mathrm{T})$ measurements taken from the human foot, specifically focused on functional assessment, based on the requirements emerged during internal debate in collaboration with rehabilitation experts.

The simplest way to determine the loads applied from outer forces or to control the forces exerted by the muscles is to measure them externally. Available systems (i.e., plantar soles equipped with sensors, baropodometric platforms) provide dynamic foot pressure measurements under static and dynamic conditions in upright conditions for posturographic analysis [15-19]. They can be used mainly in the late stages of rehabilitation and during reintegration into working and social life, when locomotion function is partially recovered. Our system focuses on the sitting posture in order to perform $\mathrm{F} / \mathrm{T}$ measurements from the foot of disabled patients seated in a wheelchair. One of the advantages of the system is its use in the first stages of rehabilitation (i.e., subacute phase), thus allowing early functional assessment.

The F/T exerted between the environment and the human body can be recorded easily with a commercially available dynamometer. From a biomechanical point of view, these measurements are the simplest but provide little information about the underlying mechanism within the body. Thus, the highly accurate and reliable data of the F/T sensors must be combined with other information from biomechanical studies.

In contrast, our system concentrates on the F/T patterns measured during the start of different ADL tasks ("drinking from a glass," "turning a key," "taking a spoon," "lifting a bag," "reaching for a bottle," and "lifting and carrying a bottle"). These ADL tasks are characterized by two reference postures of the lower limbs; the proposed system is designed to record and collect $\mathrm{F} / \mathrm{T}$ data from the patient's foot in such postures.

The subject receives instructions about the measurement protocol from a therapist. F/T data acquired during the initiation of ADL tasks are processed off-line and can then be used by clinical staff as quantitative evaluation of rehabilitation treatments. We expect that changes in the recorded $\mathrm{F} / \mathrm{T}$ patterns will delineate the course of motor recovery and verify the effectiveness of physiotherapy treatments in the future. Consequently, a simple isometric $\mathrm{F} / \mathrm{T}$ measurement has the potential to become a convenient and cost-effective solution.

In recent years, sophisticated uniaxial dynamometers have become available, although they are very expensive. In addition, only a small number of simple isometric devices have come onto the market. Securing the moving elements of an isokinetic device allows isometric $\mathrm{F} / \mathrm{T}$ data to be recorded. Obviously in this case, isometric measurements can only be made when a sophisticated and expensive isokinetic device is already available for other purposes. Isokinetic devices are capable of providing adequate information about the joint $\mathrm{F} / \mathrm{T}$ exerted by (or loaded onto) the patient. However, the imposition of artificial movements or loads and limitation to simultaneously record only one degree of freedom F/T data are major shortcomings of these devices.

In contrast, the foot platform presented in this article was designed to measure isometric F/T data from the foot and the great toe in natural start postures. One of the main clinical challenges in the rehabilitation field is to find quantitative evidence of motor recovery; the possibility of recording $\mathrm{F} / \mathrm{T}$ data is fundamental for this purpose. Currently, no purchasable device satisfies the special requirements of the foot platform. The main aim of this work-which stems from close interaction with rehabilitation experts-is development of an innovative, simple, reliable, and low-cost platform for recording F/T data during isometric exercises [20-22].

A torque-based approach has recently been proposed for quantifying atypical movements in individuals with hemiparesis [23]. Isometric measurements have been used in studies with nondisabled [24] and stroke subjects [25], but have not shown differences between the great toe and the foot for assessment purposes so far.

\section{METHODS}

\section{Subjects}

Five subacute stroke subjects, age range 62 to 83 (mean \pm standard deviation $69.0 \pm 8.9$ ) years, two men and three women, were recruited for the study. Two had right hemiparesis and three had left hemiparesis. All had experienced the acute event $25 \pm 7$ days prior to the study. Five nondisabled subjects, age range 23 to 72 (53.7 \pm 15.6) years, three men and four women, were recruited for comparison purposes. Subjects were evaluated using the Fugl-Meyer (FM) lower-limb subscore (range 0-36) and 
Motor Assessment Scale (MAS) balance sitting, sitting to standing, and walking subscores (range 3-18).

\section{Functional Requirements}

The requirements for a functional platform identified in collaboration with clinical experts were as follows:

- Able to separately measure F/T data from the whole foot and the great toe from a subject seated on a standard wheelchair. Existing references [3-4] and preliminary measurements provide physiological input ranges.

- Easy and quick to adjust according to the different anthropometrical features.

- Able to be used on both sides.

- Minimum time and physical effort required from an operator.

- Low height of the device to reduce the operator's workload.

- Able to record measurements from different postures (heel secured to the device/heel lifted). Such choice lets the patient simulate postures when he or she is asked to carry out so-called "far reaching" exercises (see "Design Approach and Ergonomic Study" section for more details).

- Can be conceived as a module to be assembled into a diagnostic device able to measure $\mathrm{F} / \mathrm{T}$ data from different anatomical districts.

\section{Design Approach and Ergonomic Study}

We followed a human-centered, mechatronic design approach by beginning from anthropometrical remarks and repetitively modifying the design choices after meetings with end-users (i.e., therapists, patients). Simulations, models, and prototypes were largely employed to acquire feedback from end-users and carry out validation tests. The proposed approach for F/T measures in isometric conditions needs an anatomically standard and fixed individual setting on the device for each patient in order to ensure reproducible, reliable, and highly precise measures.

As a reference position, the user is seated on a chair or wheelchair at $580 \mathrm{~mm}$ height from the floor of the device, the rear side of which is $330 \mathrm{~mm}$ from the user's back. For recording $\mathrm{F} / \mathrm{T}$ data during isometric exercises, the proposed platform (Figure 1) has two reference postures. Position 1 represents a neutral seated posture; most ADL tasks (i.e., grasping, lifting an object) start from this position. Other tasks can be performed starting from position 2 (i.e., forward reaching tasks). This position is characterized by a trunk bent forward and feet moved backward. Toe metatarsophalangeal flexion and ankle dorsiflexion are the joint movements of the foot that were taken into consideration. The anatomical angles for position 2 are $8^{\circ}$ for ankle dorsiflexion and $7^{\circ}$ for toe metatarsophalangeal flexion.

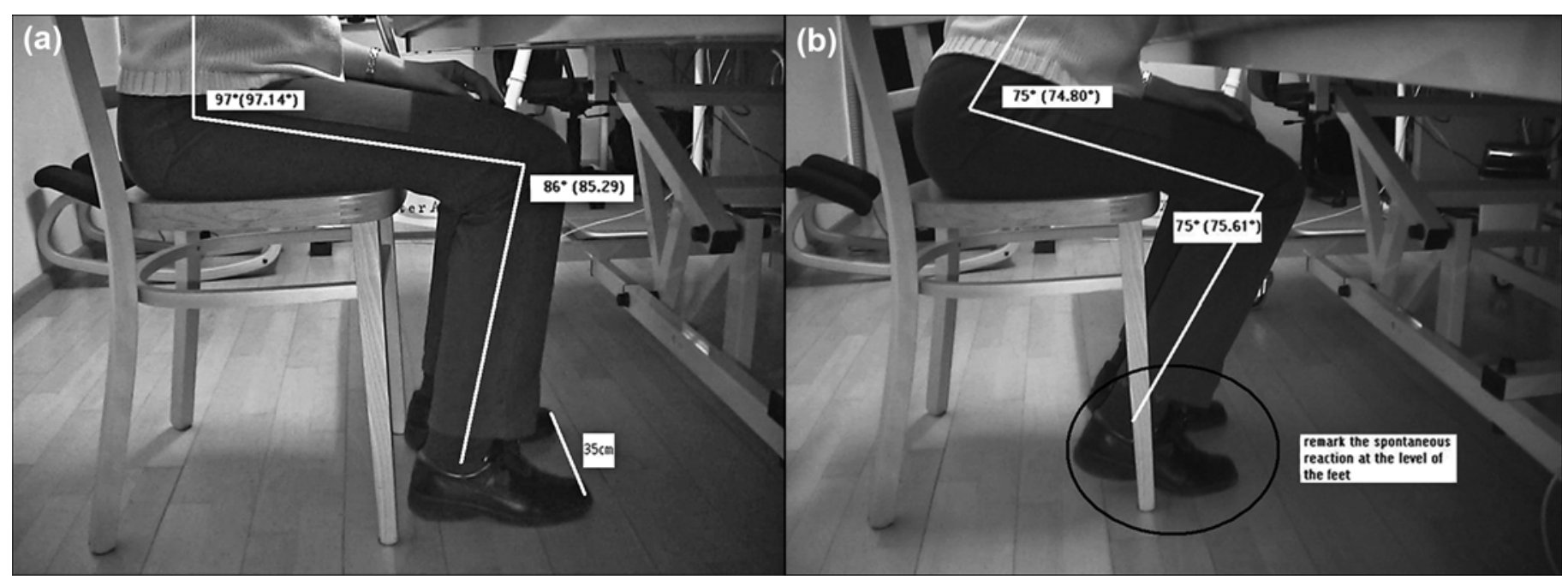

Figure 1.

Posture for two reference positions: (a) position 1, (b) position 2. (C) 2006 IEEE. Reprinted with permission from Mazzoleni S, Micera S, Romagnolo F, Dario F, Guglielmelli E. An ergonomic dynamometric foot platform for functional assessment in rehabilitation. Proceedings of the First IEEE/RAS-EMBS International Conference on Biomedical Robotics and Biomechatronics; 2006 Feb $20-22$. p. 619-24. 
An ergonomic study on the European population was carried out [26]. Computer-aided design simulations (Pro/ Engineer, Parametric Technology; Needham, Massachusetts) along with three-dimensional mannequin models (ManneQuin PRO, NextGen Ergonomics; Pointe Claire, Canada) were employed to this aim.

The ergonomic study led to the implementation of three discrete settings (small [S], medium [M], and large [L]). The $\mathrm{S}$ size is associated to the 25th percentile female, the $\mathrm{M}$ size to the mean between the 50th percentile male and 50th percentile female, and the L size to the 75th percentile male. Since the difference between the ideal anatomical angles and measured angles is $\pm 0.5^{\circ}$, the setting of the device to these percentiles can be carried out without significant errors.

The percentile values corresponding to the $\mathrm{S}, \mathrm{M}$, and $\mathrm{L}$ sizes lay on an inclined line. Contact between the foot and the platform, as well as maintenance of the two postures, is possible. Performing isometric measurements for subjects with different anthropometrical sizes is feasible, and the required adjustments are easy to perform, accomplishing the main goals of the ergonomic design.

\section{Design and Development of Device}

Based on anthropometrical and mechanical requirements, different design solutions were analyzed. The initial design stage was focused on employing a single platform equipped with two sensors for recording $\mathrm{F} / \mathrm{T}$ data from both feet. Two solutions were critically analyzed: one consisting of a single platform provided with a shifting mechanism for adjusting the toe sensor to impaired side, and one considering the foot sizes, brought to the development of a double-sized symmetric platform for the impaired side, including a shared area where the great toe of both feet can be placed. The need for repeatable measurements led to elimination of the former solution. The latter solution was validated using a mock-up (Figure 2); the area of the sensor assigned to $\mathrm{F} / \mathrm{T}$ measurements from the great toe is delimited by the red rectangle. Ease of use and stiffness represent the main advantages of this solution; moreover, adjustments are not required for positioning the great toe.

Three solutions were analyzed for processes in which the user is asked to lift the heel. The lack of contact between heel and platform characterizes one of these solutions. Close interaction with rehabilitation experts led to the conclusion that the heel does not need to be sustained by a platform.

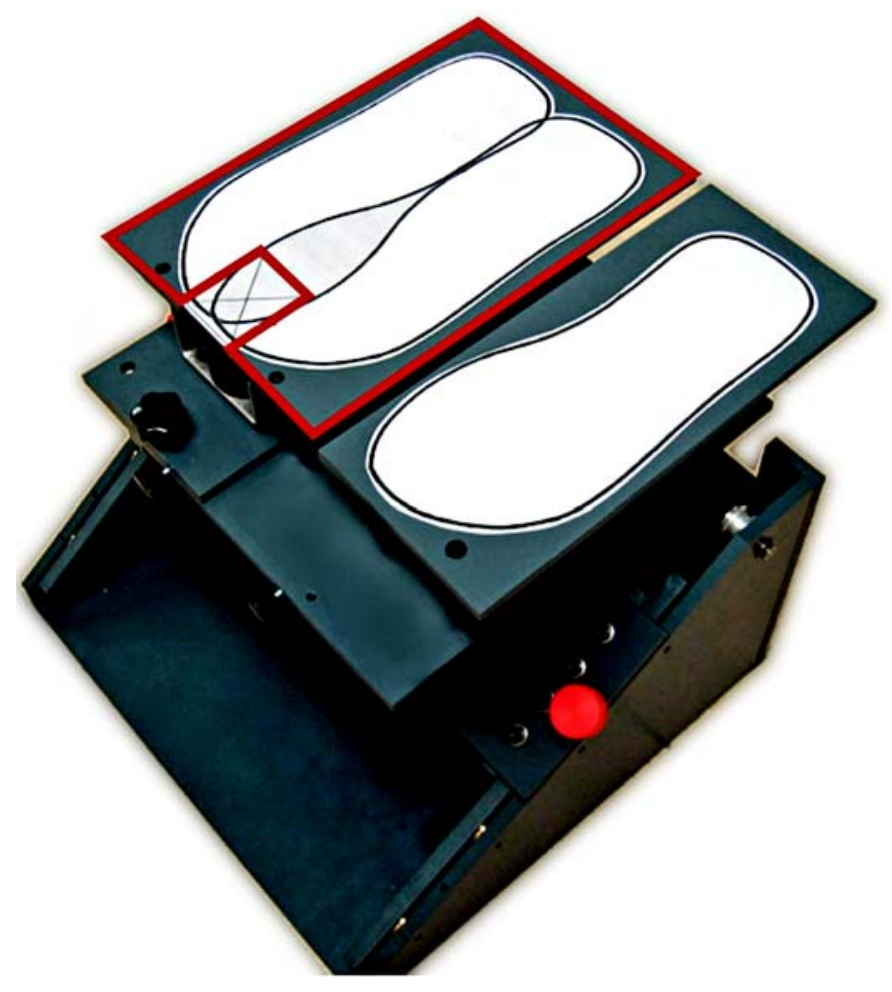

Figure 2.

First version of mock-up. Red line shows measuring platform for both sides and common position of great toe. (C) 2006 IEEE. Reprinted with permission from Mazzoleni S, Micera S, Romagnolo F, Dario F, Guglielmelli E. An ergonomic dynamometric foot platform for functional assessment in rehabilitation. Proceedings of the First IEEE/RAS-EMBS International Conference on Biomedical Robotics and Biomechatronics; 2006 Feb 20-22. p. 619-24.

Bases with continuous or discrete adjustments were identified as solutions for fitting the different anthropometrical sizes. As previously described, the adoption of three discrete settings resulted from the ergonomic analysis. Figure 3 shows a sketch of the process among different design solutions.

Base embedding of (1) horizontal and vertical rails, (2) a pipe-based sliding mechanism, and (3) a rail-based sliding mechanism were developed to solve adjustment problems. A double adjustment to fit the different heights of patients allows the operator to change the position of the platform using both the vertical and the horizontal rail in order to fix it in the appropriate setting. The second and third solutions are characterized by a sliding mechanism that allows the operator to perform a single adjustment. The mechanical structure of the second solution is based 


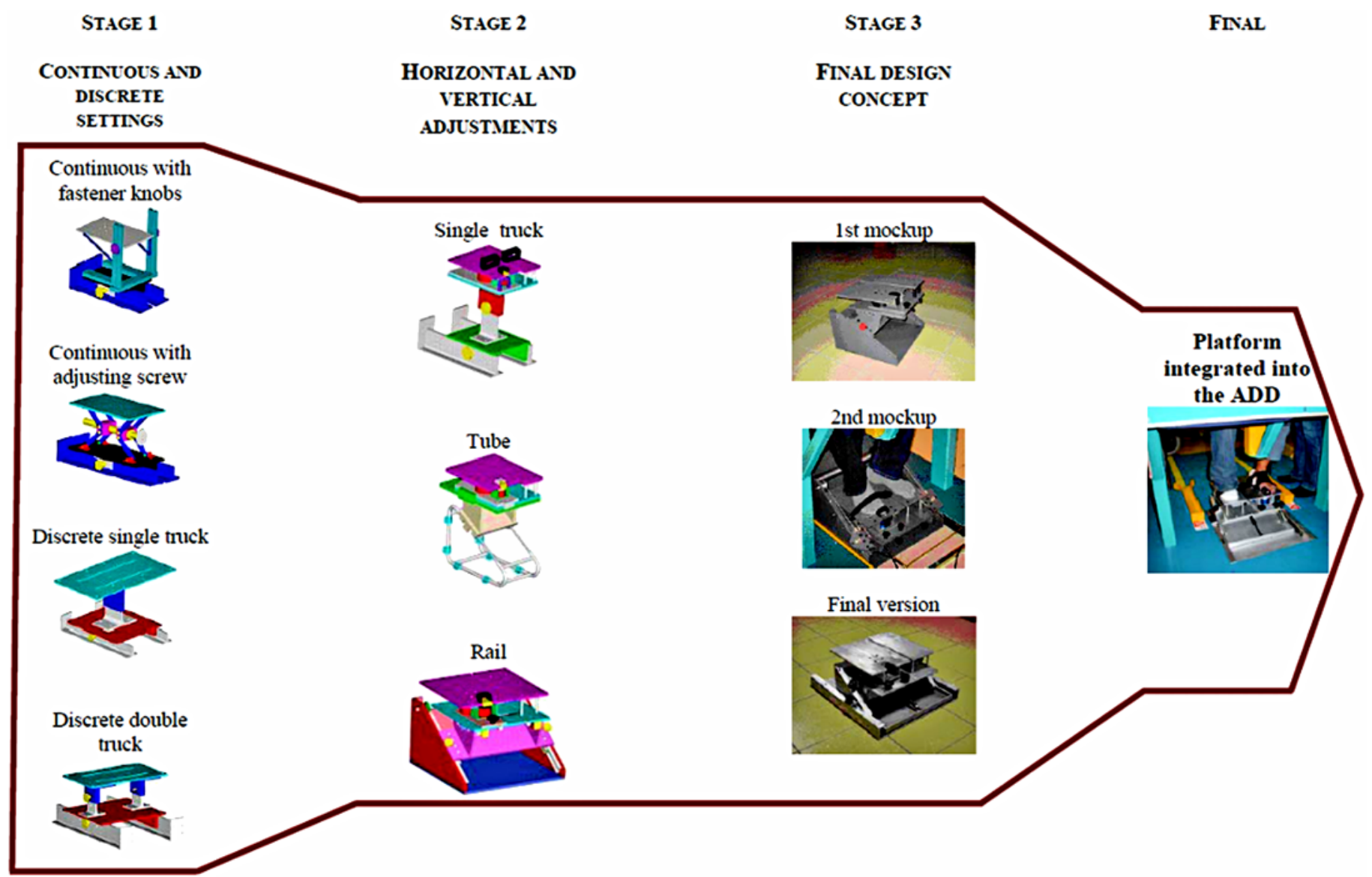

Figure 3.

Design process for mechatronic platform ADD = Alladin Diagnostic Device.

on metallic pipes arranged on a triangular shape. The sliding mechanism in the third solution is achieved by placing two rails on corresponding triangular lateral walls. In both cases, the platform can be moved up and down along the inclined side. The requirements for elevated robustness, reduced encumbrance, ergonomic constraints, usability, and safety led to the choice of the rail-based sliding mechanism as the final design choice. Figure 3 shows the three versions of the final design concept, developed during an iterative approach.

An early prototyping technique was used: two models in polyvinyl chloride (PVC) were manufactured, validated by real patients and rehabilitation experts, and modified. The final version, manufactured in aluminum, emerged from the initial two mock-ups. The first version of the foot platform, though rather bulky, was simple and robust. The distance between the user and the device was $690 \mathrm{~mm}$.
A second version was developed to reduce the operator's physical effort while setting the device by redesigning the sliding mechanism and by providing a counterbalance mechanism. The distance between the user and the device was $600 \mathrm{~mm}$. Starting from remarks obtained from rehabilitation experts, we redesigned the final version of the device. Its structure is robust and not bulky. The two sloped surfaces and the platforms can be pushed back to be set in position 2 . The distance between the user and the device is $580 \mathrm{~mm}$. Different views of the foot platform with dimensions are shown in Figure 4.

The different heights of the mechatronic device from the floor for the three discrete settings are height $(\mathrm{H}) 1=168$ $\mathrm{mm}$ for the L size, H2 = $204 \mathrm{~mm}$ for the $\mathrm{M}$ size, and H3 = $240 \mathrm{~mm}$ for the $\mathrm{S}$ size. The difference between the height of the user from the foot platform (HU) and the height of the device from the floor (i.e., $\mathrm{HL}=\mathrm{HU}-\mathrm{H} 1=412 \mathrm{~mm}, \mathrm{HM}=$ $\mathrm{HU}-\mathrm{H} 2=376 \mathrm{~mm}$, HS = HU - H3 = $340 \mathrm{~mm}$ ) complies 
(a)

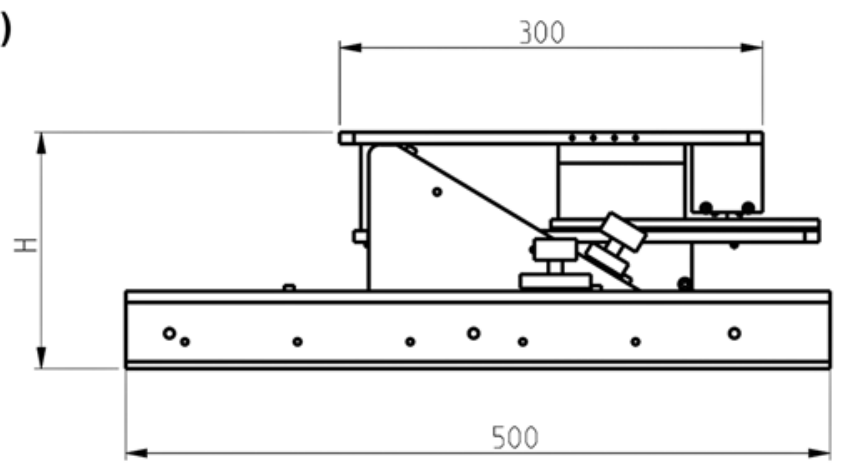

(b)

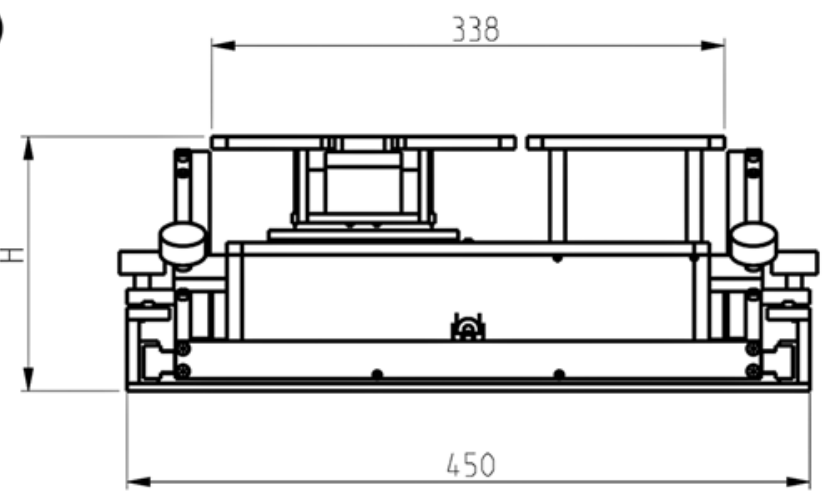

(c)

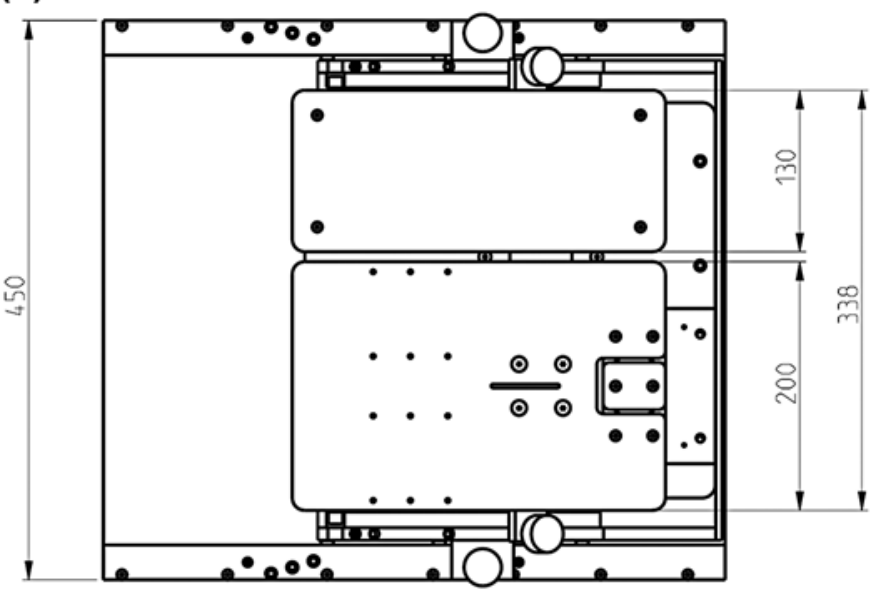

Figure 4.

(a) Lateral view, (b) frontal view, and (c) top view of foot platform with dimensions expressed in millimeters $(H$ is variable height for three different settings).

with the anthropometrical data in the specified range of population [27] and keeps the foot in contact with the platform during the isometric measurements. Thanks to the design choices, usability was improved and manufacturing was simpler. A gas spring was inserted as a counterbalance mechanism in order to provide a smooth movement when changing the setting to fit the patient's size. This choice reduces the operator's effort.

\section{Functional Specifications}

The device is capable of recording $\mathrm{F} / \mathrm{T}$ data during isometric exercises. Two 6-axis sensors are embedded into the platform: the former measures $\mathrm{F} / \mathrm{T}$ from the foot and the latter from the great toe. To this aim, commercial sensors were used (50M31A-I25 for the foot and 90M40A-I50 for the great toe, JR3 Inc; Woodland, California). The sensors' technical specifications are shown in Table 1. The sensors are monolithic aluminum devices containing analog and digital electronic systems. Data are transmitted to the receiver electronics in a synchronous serial format. A commercial digital-signal-processingbased force sensor receiver board provides 6 degree-offreedom $\mathrm{F} / \mathrm{T}$ data; each sensor can provide digitally filtered data at $8 \mathrm{kHz}$ per channel.

A custom driver enables configuration of the receiver boards and reading of the $\mathrm{F} / \mathrm{T}$ data. It also provides buffering of the acquired data. Buffering is essential for the proper acquisition of $\mathrm{F} / \mathrm{T}$ since receiver boards buffer only the very last sample for each sensor. The sampling frequency for the foot platform is $100 \mathrm{~Hz}$. A software application was developed for setup and integrity checking of the sensors. It is used during initial setup of the system and in case the data acquisition module reports an error (i.e., a sensor not plugged correctly into a receiver board). During setup of the diagnostic device, the software application is also used to read the serial number of F/T sensors.

The device is composed of two sloped surfaces and a sliding base platform. Two platforms are placed on the base platform. One features two sensors measuring the F/T from the impaired foot, and the other sustains the unimpaired foot. The base platform can be moved along the two sloped surfaces so that the requested posture can be maintained during adjustments for fitting the patient's size. The base platform can be pushed up or down along the sloped surfaces and secured with two fastener knobs (one for each

Table 1.

Basic characteristics of 6-axis force/torque sensors.

\begin{tabular}{|c|c|c|c|}
\hline Description & $\begin{array}{c}\text { Lateral Forces } \\
\left(F_{x}, F_{y}\right) \\
(\mathrm{N})\end{array}$ & $\begin{array}{l}\text { Axial Force } \\
\left(F_{z}\right) \\
(\mathrm{N})\end{array}$ & $\begin{array}{c}\text { Torques } \\
\left(T_{x}, T_{y}, T_{z}\right) \\
(\mathrm{Nm})\end{array}$ \\
\hline Type-Foot & 400 & 800 & 25 \\
\hline Tyре-Тое & 150 & 300 & 8 \\
\hline
\end{tabular}


side of the base platform). The change of the three settings can be carried out smoothly thanks to a gas spring counterbalancing the base platform's weight (Figure 5).

The device is capable of measuring $\mathrm{F} / \mathrm{T}$ data from the right and left foot thanks to the implementation of an exchange mechanism between the two platforms. Simple and quick operations consisting of (1) locking/unlocking two fastener knobs, (2) exchanging the two platforms, and (3) pushing/pulling the foot platform for passing from position 1 to position 2 (and vice-versa) allow the operator to properly set the device.

\section{RESULTS}

The platform was incorporated into the Alladin Diagnostic Device [22], capable of measuring F/T data from eight body districts during isometric exercises (Figure 5). Table 2 shows the force values (foot and great toe sensor) during the ADL task "lifting a bottle" on nondisabled subjects for comparison purposes. Table $\mathbf{3}$ shows mean force

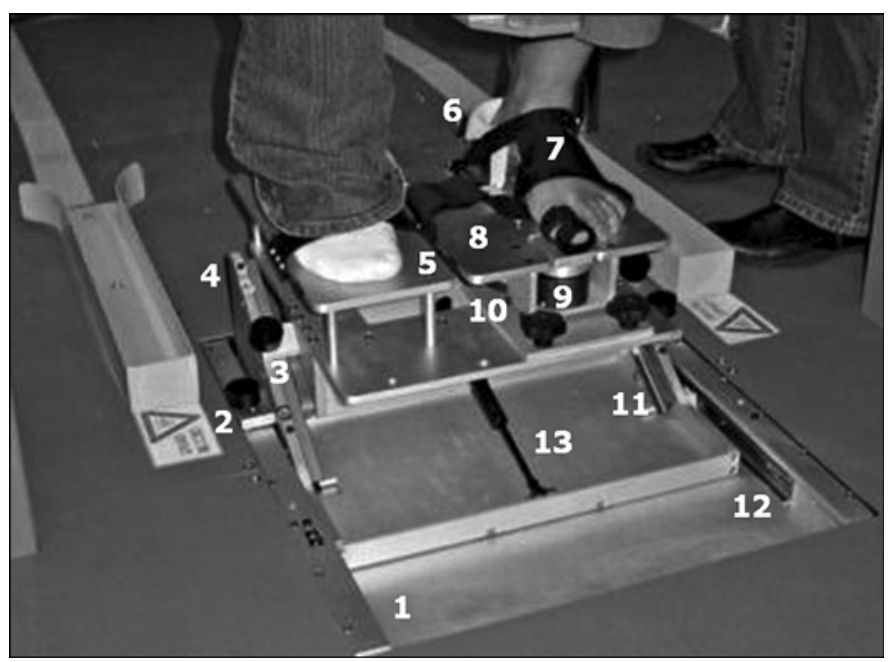

Figure 5.

Foot device integrated into Alladin Diagnostic Device: (1) base platform, (2) fastener knob for horizontal movements, (3) fastener knob for movements along inclined plane, (4) inclined wall, (5) supporting platform, (6) heel support, (7) velcro strips, (8) measuring platform, (9) great toe sensor, (10) foot sensor, (11) rail based sliding mechanism, (12) horizontal rails, (13) gas spring. Figure originally appears in Mazzoleni S, Toth A, Munih M, Van Vaerenbergh J, Cavallo G, Micera S, Dario P, Guglielmelli E. Whole-body isometric force/torque measurement for functional assessment in neuro-rehabilitation: Platform design development and verification. J NeuroEng Rehabil. 2009;6:38.
Table 2.

Mean force values from foot and great toe sensor during activity of daily living task "lifting a bottle" in seven nondisabled subjects

\begin{tabular}{lcc}
\hline \multicolumn{1}{c}{ Side } & $\begin{array}{c}\text { Foot Sensor } \\
(\mathbf{N})\end{array}$ & $\begin{array}{c}\text { Great Toe Sensor } \\
\text { (N) }\end{array}$ \\
\hline Right & 56.390 & 9.399 \\
Left & 61.019 & 7.251 \\
\hline \hline
\end{tabular}

values (foot and great toe sensor) during the ADL task "lifting a bottle" on PSs, along with FM and MAS scores. Figure 6 and Figure 7 show the force values in PSs at admission, midtreatment, and discharge measured from the foot and great toe, respectively. Similar results were obtained from other ADL tasks. Recorded F/T data confirm that the requirements emerged during the design process were completely satisfied:

1. F/T ranges comply with available data [28-29].

2. The sensors' accuracy is enough to consider the different anthropometrical sizes and weights of the recruited subjects.

Table 3.

Mean force values and Fugl-Meyer (FM) and Motor Assessment Scale (MAS) scores from foot and great toe sensor during activity of daily living task "lifting a bottle" in 5 poststroke patients (PSs).

\begin{tabular}{ccccc}
\hline \multicolumn{1}{c}{ Subject } & $\begin{array}{c}\text { Foot Mean } \\
\text { Force (N) }\end{array}$ & $\begin{array}{c}\text { Great Toe } \\
\text { Mean Force (N) }\end{array}$ & FM & MAS \\
\hline PS01 (left) & 60.286 & 1.756 & 33 & 17 \\
Admission & 63.853 & 3.275 & 36 & 18 \\
Midtreatment & 63.731 & 6.358 & 36 & 18 \\
Discharge & & & & \\
PS02 (left) & 42.055 & 14.032 & 28 & 16 \\
Admission & 41.695 & 9.697 & 32 & 18 \\
Midtreatment & 64.521 & 11.165 & 34 & 18 \\
Discharge & & & & \\
PS03 (left) & 61.082 & 6.168 & 33 & 18 \\
Admission & 78.219 & 4.145 & 35 & 18 \\
Midtreatment & 72.020 & 4.696 & 36 & 18 \\
Discharge & & & & \\
PS04 (right) & 56.147 & 10.257 & 20 & 13 \\
Admission & 53.434 & 4.607 & 34 & 18 \\
Midtreatment & 57.703 & 3.785 & 36 & 18 \\
Discharge & & & & \\
PS05 (right) & 59.239 & 6.738 & 34 & 12 \\
Admission & 63.884 & 3.738 & 34 & 13 \\
Midtreatment & 59.853 & 9.287 & 34 & 13 \\
Discharge & 56. & & & \\
\hline FM: lower limb range $=0-36$. & & & \\
MAS: Balance sitting + Sitting to Standing + Walking: range $=3-18$. & \\
\hline \hline
\end{tabular}




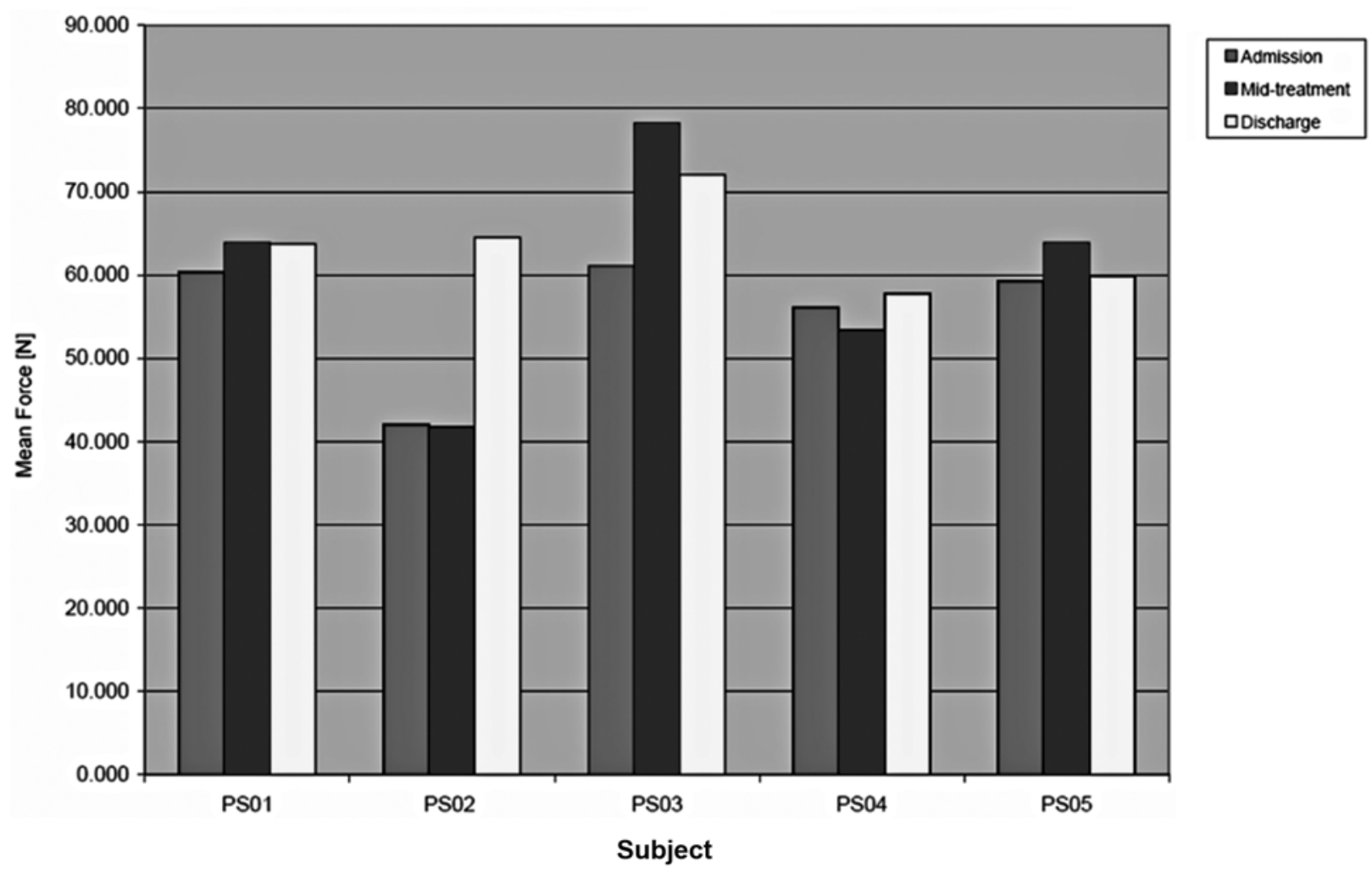

Figure 6.

Force values in five poststroke patients (PSs) from foot sensor.

The increasing trend in the $\mathrm{F} / \mathrm{T}$ values measured from the foot of five PSs between admission (2-8 weeks after the stroke event) and discharge (25-32 weeks of physiotherapy treatments) is accompanied by an increase in FM and MAS scores collected at the same times (except for FM and MAS scores that remain unchanged in PS05 and PS03, respectively).

A preliminary comparison between values recorded in PSs and nondisabled subjects showed that different trends can be observed because of high intersubject variability. For instance, PS02 showed an increase in forces between admission and discharge. At the end of treatment, the force value was close to the mean value recorded in nondisabled subjects. A similar positive trend was observed in PS01, although the initial force value was already close to that of nondisabled subjects.

Force values in PS03 at midtreatment and discharge were much higher than those recorded in nondisabled subjects. These high values could be related to possible motor compensation mechanisms, typical in PSs, which result in abnormal joint torque and force patterns.
The force values in PS04 and PS05 at admission and discharge were close to those recorded in nondisabled subjects, with substantial difference at midtreatment. In PS04, the value at midtreatment was lower than that recorded at discharge but lower than that at admission. In PS05, the value at midtreatment was higher than that at admission but even at discharge. A large experimental trial is needed to provide a clinical interpretation of data.

\section{DISCUSSION}

Measurements from the human foot during ADL tasks (e.g., reaching tasks) can provide important information to understand recovery mechanisms after an injury. The proposed system complies with the presented clinical and functional specifications and allows recording of $\mathrm{F} / \mathrm{T}$ data from the human foot and great toe. Moreover, the platform was accepted by the physiatrists and therapists who used it during the experimental trials.

The results show that the F/T signals from the foot and the great toe are characterized by different trajectories, both 


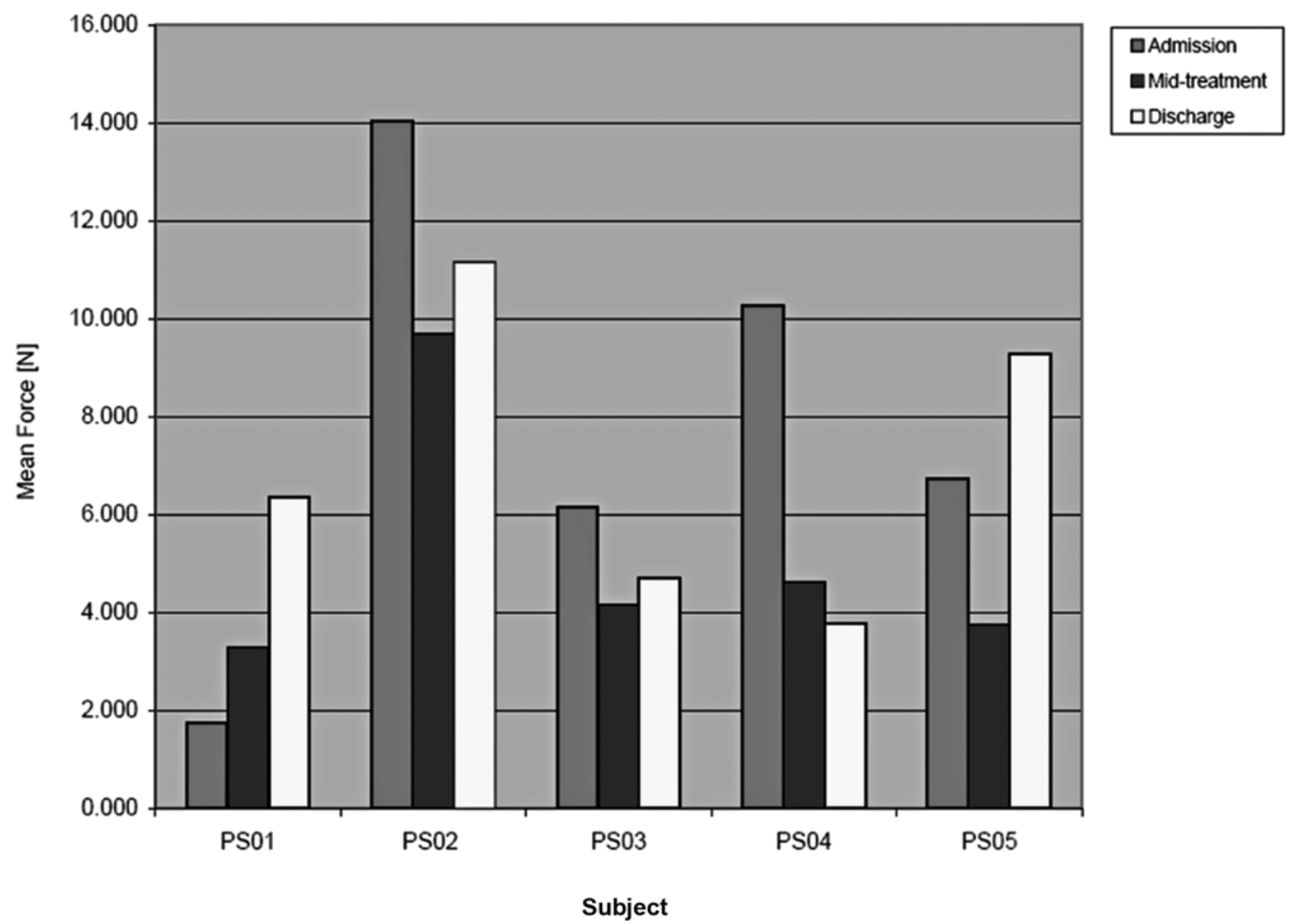

Figure 7.

Force values in five poststroke patients (PSs) from great toe sensor.

in individuals with hemiparesis and in nondisabled subjects. Moreover, the recorded F/T measurements from the great toe are significant and within the physiological human range. The pilot data collected so far show differences between measurements from the foot and the great toe. Their clinical interpretation will be assessed by medical experts in the future. The preliminary outcomes demonstrate that the device is capable of recording F/T measurements representing ADL tasks. In any case, at this stage, it is not possible to make clinical conclusions on such a small amount of data. A large clinical trial has been planned that, alongside the sitting posture, will record forces in standing or quasistatic positions.

Starting from the data collected using the device, statistical features characterizing clinical recovery can be extracted and used by data mining algorithms to provide probabilistic information about the motor recovery process.

We hypothesize that by tracking the effects of rehabilitation of the foot and great toe in PSs, milestones in the recovery process and predictive markers for functional improvement in stroke can be discovered.

Possible uses of the foot device, which will be sustained by future clinical studies, are-

1. Isometric motor exercise. The execution of isometric exercises is often required by clinical procedures for assessment purposes. The foot device can also be used as biofeedback of $\mathrm{F} / \mathrm{T}$ data recorded during isometric exercises.

2. Human-machine interface (HMI). The presented device can be used as innovative HMI for different applications in which the use of the foot is required, 
e.g., pedal interfaces for games, guidance simulations, and robotic systems for surgery.

This device can also be used in conjunction with virtual reality environments for foot rehabilitation, as recently proposed for the upper limb [30].

\section{CONCLUSIONS}

This study presented a novel mechatronic device for recording $\mathrm{F} / \mathrm{T}$ data under isometric conditions from the human foot during ADL tasks, along with experimental pilot data. The design and development process was accompanied by close interaction with medical researchers. The proposed platform can be used effectively in the functional assessment of PSs. The results presented in this study show high intersubject variability in the different stages (i.e., admission, midtreatment, discharge). Future clinical studies will be able to identify motor recovery mechanisms in PSs through comparison with data recorded in nondisabled subjects. The foot platform is able to quantitatively describe ADL tasks. The platform can also be used as a tool for motor therapy and foot-based HMI. The ergonomic features of the platform, which is able to collect foot and great toe F/T measurements of PSs, facilitate the operators' job in terms of time and physical effort.

\section{ACKNOWLEDGMENTS}

\author{
Author Contributions: \\ Study concept and design: S. Mazzoleni, E. Guglielmelli. \\ Acquisition of data: J. Van Vaerenbergh, E. Stokes, G. Fazekas. \\ Analysis and interpretation of data: S. Mazzoleni. \\ Drafting of manuscript: S. Mazzoleni, E. Guglielmelli. \\ Study supervision: J. Van Vaerenbergh, P. Dario. \\ Financial Disclosures: The authors have declared that no competing \\ interests exist. \\ Funding/Support: This material is based on work partly supported \\ by the European Commission 6th Framework Programme (grant \\ 507424). \\ Additional Contributions: The ALLADIN project was coordinated \\ by Jo Van Vaerenbergh, Arteveldehogeschool (Gent, Belgium). The \\ other partners of the ALLADIN project are Language and Computing \\ NV (Belgium), Budapest University of Technology and Economics \\ (Hungary), Faculty of Electrical Engineering at the University of \\ Ljubljana (Slovenia), Zenon SA Robotics and Informatics (Greece), \\ Multitel ASBL (Belgium), Trinity College Dublin (Ireland), National \\ Institute for Medical Rehabilitation (Hungary), Scuola Superiore \\ Sant’Anna (Italy), and Università Campus Bio-Medico (Italy).
}

Institutional Review: This study was approved by the ethical committees of (1) Algemeen Ziekenhuis Maria Middelares-Sint Jozef, Gent, Belgium; (2) Adelaide and Meath Hospital, Tallaght, Dublin, Ireland; and (3) Szent János Hospital, Budapest, Hungary. Informed consent was obtained from each participant.

Participant Follow-Up: The authors do not plan to inform participants of the publication of this study. However, participants have been encouraged to check the study Web site for updated publications.

\section{REFERENCES}

1. Cavanagh PR, Ulbrecht JS. Biomechanics of the diabetic foot: a quantitative approach to the assessment of neuropathy, deformity, and plantar pressure. In: Jahss MH, editor. Disorders of the foot and ankle: medical and surgical management. 2nd ed. Vol 2. Philadelphia (PA): W. B. Saunders; 1991. p. 1864-1907.

2. Nene AV, Evans GA, Patrick JH. Simultaneous multiple operations for spastic diplegia. Outcome and functional assessment of walking in 18 patients. J Bone Joint Surg Br. 1993;75(3):488-94. [PMID:8496229]

3. Jackson AB, Carnel CT, Ditunno JF, Read MS, Boninger ML, Schmeler MR, Williams SR, Donovan WH; Gait and Ambulation Subcommittee. Outcome measures for gait and ambulation in the spinal cord injury population. J Spinal Cord Med. 2008;31(5):487-99. [PMID:19086706]

4. Laurent G, Valentini F, Loiseau K, Hennebelle D, Robain G. Claw toes in hemiplegic patients after stroke. Ann Phys Rehabil Med. 2010;53(2):77-85. [PMID:20097630]

5. Lee MY, Lin CF, Soon KS. New foot pressure activated sensory compensation system for posture-control enhancement in amputees. IEEE/ASME Trans Mechatron. 2007;12:236-43. http://dx.doi.org/10.1109/TMECH.2007.897234

6. Carrozza MC, Persichetti A, Laschi C, Vecchi F, Lazzarini R, Vacalebri P, Dario P. A wearable biomechatronic interface for controlling robots with voluntary foot movements. IEEE/ASME Trans Mechatron. 2007;12:1-11. http://dx.doi.org/10.1109/TMECH.2006.886250

7. Said CM, Goldie PA, Patla AE, Sparrow WA. Effect of stroke on step characteristics of obstacle crossing. Arch Phys Med Rehabil. 2001;82(12):1712-19.

[PMID:11733887] http://dx.doi.org/10.1053/apmr.2001.26247

8. Lanzetta D, Cattaneo D, Pellegatta D, Cardini R. Trunk control in unstable sitting posture during functional activities in healthy subjects and patients with multiple sclerosis. Arch Phys Med Rehabil. 2004;85(2):279-83. [PMID:14966714] http://dx.doi.org/10.1016/j.apmr.2003.05.004

9. Bozec SL, Goutal L, Bouisset S. [Dynamic postural adjustments associated with the development of isometric forces 
in sitting subjects]. C R Acad Sci III. 1997;320(9):715-20. French. [PMID:9377177]

10. Chung SG, van Rey EM, Bai Z, Rogers MW, Roth EJ, Zhang LQ. Aging-related neuromuscular changes characterized by tendon reflexes system properties. Arch Phys Med Rehabil. 2003;86(2):318-27. [PMID: 15706561] http://dx.doi.org/10.1016/j.apmr.2004.04.048

11. Kirsch RF, Acosta AM, Perreault EJ, Keith MW. Measurement of isometric elbow and shoulder moments: positiondependent strength of posterior deltoid-to-triceps muscle tendon transfer in tetraplegia. IEEE Trans Rehabil Eng. 1996;4(4):403-9. [PMID:8973966] http://dx.doi.org/10.1109/86.547942

12. Deutsch JE, Latonio J, Burdea G, Boian R. Post-stroke rehabilitation with the Rutgers ankle system - A case study. Presence MIT Press. 2001;10(4):416-30.

13. Schmidt H, Hesse S, Bernhardt R, Krüger J. HapticWalkera novel haptic foot device. ACM Trans Appl Percept. 2005;2:166-80. http://dx.doi.org/10.1145/1060581.1060589

14. Saglia JA, Tsagarakis NG, Dai JS, Caldwell DG. A high performance redundantly actuated parallel mechanism for ankle rehabilitation. Int J Robot Res. 2009;28:1216-27. http://dx.doi.org/10.1177/0278364909104221

15. Teyhen DS, Stoltenberg BE, Eckard TG, Doyle PM, Boland DM, Feldtmann JJ, McPoil TG, Christie DS, Molloy JM, Goffar SL. Static foot posture associated with dynamic plantar pressure parameters. J Orthop Sports Phys Ther. 2011;41(2):100-107. [PMID:20972342]

16. Baszczyk JW, Orawiec R. Assessment of postural control in patients with Parkinson's disease: sway ratio analysis. Hum Mov Sci. 2011;30(2):396-404. [PMID:20800915] http://dx.doi.org/10.1016/j.humov.2010.07.017

17. van Nes IJ, Nienhuis B, Latour H, Geurts AC. Posturographic assessment of sitting balance recovery in the subacute phase of stroke. Gait Posture. 2008;28(3):507-12.

[PMID:18424149] http://dx.doi.org/10.1016/j.gaitpost.2008.03.004

18. Genthon N, Rougier P, Gissot AS, Froger J, Pélissier J, Pérennou D. Contribution of each lower limb to upright standing in stroke patients. Stroke. 2008;39(6):1793-99. [PMID:18369174] http://dx.doi.org/10.1161/STROKEAHA.107.497701

19. Rogind H, Christensen J, Danneskiold-Samsøe B, Bliddal H. Posturographic description of the regaining of postural stability following stroke. Clin Physiol Funct Imaging. 2005; 25(1):1-9. [PMID:15659073]

http://dx.doi.org/10.1111/j.1475-097X.2004.00553.x

20. Mazzoleni S, Toth A, Munih M, Van Vaerenbergh J, Cavallo G, Micera S, Dario P, Guglielmelli E. Whole-body isometric force/torque measurements for functional assessment in neuro-rehabilitation: platform design, development and verification. J Neuroeng Rehabil. 2009;6:38.

\section{[PMID:19878556]}

http://dx.doi.org/10.1186/1743-0003-6-38

21. Van Vaerenbergh J, Mazzoleni S, Toth A, Guglielmelli E, Munih M, Stokes E, Fazekas G, Ruijter SD. Assessment of recovery at stroke patients by whole-body isometric forcetorque measurement of functional tasks I: mechanical design of the device. Proceedings of the 3rd European Medical and Biological Engineering Conference; 2005; Prague, Czech Republic.

22. Mazzoleni S, Micera S, Romagnolo F, Dario P, Guglielmelli E. An ergonomic dynamometric foot platform for functional assessment in rehabilitation. Proceedings of the 1st IEEE/ RAS-EMBS International Conference on Biomedical Robotics and Biomechatronics; 2006; Pisa, Italy. p. 619-24.

23. Dewald JP, Beer RF. Abnormal joint torque patterns in the paretic upper limb of subjects with hemiparesis. Muscle Nerve. 2001;24(2):273-83. [PMID:11180211]

http://dx.doi.org/10.1002/10974598(200102)24:2<273::AID-MUS130>3.0.CO;2-Z

24. Bobet J, Gossen ER, Stein RB. A comparison of models of force production during stimulated isometric ankle dorsiflexion in humans. IEEE Trans Neural Syst Rehabil Eng. 2005;13(4):444-51. [PMID:16425825] http://dx.doi.org/10.1109/TNSRE.2005.858461

25. Carlsson U, Henning GB, Svantesson U, Sunnerhagen KS. Plantar flexor muscle action while sitting, standing and prone in patients with upper motor neuron lesion due to stroke. Isokinet Exerc Sci. 2003;11(4):205-11.

26. Peebles L, Norris BJ; Adultdata. The handbook of adult anthropometrical and strength measurements-Data for design safety. London (UK): Department of Trade and Industry; 1998.

27. National Aeronautics and Space Administration. Anthropometry and biomechanics [Internet]. Washington (DC): NASA; 2008. Available from: http://msis.jsc.nasa.gov/sections/ section03.htm

28. Brunt D, Greenberg B, Wankadia S, Trimble MA, Shechtman $O$. The effect of foot placement on sit to stand in healthy young subjects and patients with hemiplegia. Arch Phys Med Rehabil. 2002;83(7):924-29. [PMID:12098151] http://dx.doi.org/10.1053/apmr.2002.3324

29. Hayafune N, Hayafune Y, Jacob HA. Pressure and force distribution characteristics under the normal foot during the push-off phase in gait. Foot. 1999;9:88-92. http://dx.doi.org/10.1054/foot.1999.0518

30. Kurillo G, Mihelj M, Munih M, Bajd T. Multi-fingered grasping and manipulation in virtual environment using isometric finger device. Presence MIT Press. 2007;16(3): 293-306. http://dx.doi.org/10.1162/pres.16.3.293

Submitted for publication March 28, 2011. Accepted in revised form December 28, 2011. 
JRRD, Volume 49, Number 6, 2012

This article and any supplementary material should be cited as follows:

Mazzoleni S, Van Vaerenbergh J, Stokes E, Fazekas G, Dario P, Guglielmelli E. An ergonomic modular foot platform for isometric force/torque measurements in poststroke functional assessment: A pilot study. J Rehabil
Res Dev. 2012;49(6):949-60.

http://dx.doi.org/10.1682/JRRD.2011.03.0059

ResearcherID: Stefano Mazzoleni, PhD: B-5875-2011 